\title{
The Association Between Eating Green Vegetables Every Day And Mild Cognitive Impairment: A Community-Based Cross-Sectional Study In Shanghai
}

This article was published in the following Dove Press journal:

Neuropsychiatric Disease and Treatment

\author{
Wei $\mathrm{Li}^{1,2, *}$ \\ Lin Sun ${ }^{1,2, *}$ \\ Ling Yue ${ }^{1,2}$ \\ Guanjun $\mathrm{Li}^{1,2}$ \\ Shifu Xiao ${ }^{1,2}$ \\ 'Department of Geriatric Psychiatry, \\ Shanghai Mental Health Center, Shanghai \\ Jiao Tong University School of Medicine, \\ Shanghai, People's Republic of China; \\ ${ }^{2}$ Alzheimer's Disease and Related \\ Disorders Center, Shanghai Jiao Tong \\ University, Shanghai, People's Republic of \\ China
}

*These authors contributed equally to this work
Correspondence: Guanjun Li; Shifu Xiao Department of Geriatric Psychiatry, Shanghai Mental Health Center, Shanghai Jiao Tong University School of Medicine, Shanghai, People's Republic of China Email liguanjun66@I26.com; xiaoshifu@msn.com
Background: Emerging evidence has suggested that green vegetables may prevent cognitive decline.

Methods: We examined the cross-sectional association between green vegetables intake and mild cognitive impairment (MCI) using data from 525 participants aged 55 years and above from the China Longitudinal Aging Study (CLAS) in Shanghai.

Results: Compared with participants who did not eat green vegetables every day, those who had consumed green vegetables every day had a significantly lower risk of mild cognitive impairment (MCI) $(\mathrm{OR}=0.218,95 \% \mathrm{CI}, 0.116-0.411, \mathrm{p}<0.001)$, and this association was independent of age, education, having hobbies, surfing the Internet, sleep time per night (youth), long-term residency and consumption of specific red food, such as meat, bread, bean curd, and ginger.

Conclusion: In summary, using community-based data in Shanghai, we found out that subjects who eat green vegetables every day have significantly lower odds of $\mathrm{MCI}$ than those who do not eat every day. Based on current evidence, we propose that eating green vegetables every day might be a potential preventive measure to slow cognitive decline and neurodegeneration in the elderly.

Keywords: elderly, Chinese, dietetic association, green vegetables, cognitive impairment

\section{Introduction}

Emerging evidence has suggested that green vegetables may prevent cognitive decline. $^{1-3}$ For example, Kang et $\mathrm{al}^{4}$ pointed out that more green vegetable intake was significantly associated with less cognitive decline, but their conclusion was only limited to aging women. Polidori et $\mathrm{al}^{5}$ also confirmed that healthy subjects of any age with a high daily intake of vegetables, had higher antioxidant levels, lower levels of biomarkers of oxidative stress as well as better cognitive performance than those who consumed low amounts of vegetables.

Up to now, no research has been done on the relationship between green vegetables consumption and cognitive function in China. Therefore, we conducted this cross-sectional study to explore the cognitive protective effects of green vegetables among the elderly in Chinese communities.

\section{Materials And Methods Population Study}

This cross-sectional population-based study was carried out in Xinjing, Shanghai (China), between June 1 and August 31, 2013, and the method of sampling has been described in our previous studies. ${ }^{6}$ All 55- to 95-year-olds born between June 1, 1916, 
and August 31, 1961, and registered for census purposes in Shanghai were invited to participate in the study. The inclusion criteria involved participants who (1) were 55 years old and above; (2) had no serious physical illness, such as severe infection, acute myocardial infarction, acute cerebral infarction and tumors, or serious mental illness, such as mental retardation and schizophrenia; and (3) agreed to participate in the study.

Exclusion criteria were (1) participants who had serious physical illness or serious mental illness; (2) participants who suffered from severe visual or hearing impairment; and (3) refusal of the participants or their guardians to participate in the study. All the participants had signed an informed consent before the study was initiated and we had gotten an ethical review and approval from Shanghai Mental Health Centre. This study was conducted in accordance with the principles of Declaration of Helsinki.

\section{Green Vegetables Consumption}

By using the food frequency questionnaire (FFQ), ${ }^{7}$ we obtained the information about participants' dietary consumption habits and frequency of consumption of green vegetables. The question "how often do you eat green vegetables?" was used in the interview. Responses were recorded as daily (for those who consumed green vegetables at least 1 time per day), weekly (for those who consumed green vegetables 1-6 times per week), or monthly (for those who consumed green vegetables less than 1 time per week).

Green vegetables intake frequencies were calculated on a weekly basis (calculated from daily, weekly and monthly recordings, e.g., green vegetables once/day, every day $=7$ times/week; green vegetables once/month $=0.25$ times/ week, etc.). Using the same method, we have also investigated data on the consumption of meat, bread, bean curd, and ginger.

\section{Assessments}

This study consisted of two parts. Firstly, we collected general demographic data (age, sex, education, long-term residency, and living habits) of the subjects in the form of face-to-face interviews (contingent valuation study method). Then, we determined if the participant had $\mathrm{MCI}$, and the diagnostic criteria for $\mathrm{MCI}^{8}$ were as follows: (1) memory complaints; (2) objective memory impairment; (3) normal general cognitive function; (4) daily activities are well preserved; and (5) absence of dementia.

At the same time, we also used the Mini-Mental State Examination $(\mathrm{MMSE})^{9}$ and the Montreal Cognitive
Assessment (MoCA $)^{10}$ to assess the cognitive function of those subjects. The Chinese version of the $\mathrm{MMSE}^{11}$ diagnosed MCI patients whose MMSE scores were higher than or equal to 25,21 , or 18 if they had secondary and higher education, an elementary school education, or no education, respectively. A diagnosis of $\mathrm{AD}$ in the present study was characterized by MMSE scores below 25, 21, or 18 for participants who had a middle school or higher education, an elementary school education, or no education, respectively. All of our scales were assessed by experienced clinical psychology staff who have consistently trained prior to the project.

Based on the above diagnostic criteria, 530 people were enrolled in the study, while 5 were excluded (including 2 schizophrenia, 2 severe depression, and 1 acute myocardial infarction). Of the 525 participants, 14 were diagnosed with dementia, 101 were diagnosed with MCI, 406 were considered as normal elderly, and 4 diagnostic data were missing. Then, we explored the relationship between green vegetables and MCI, and the flow chart is shown in Figure 1.

\section{Data Analysis}

Categorical variables were expressed as frequencies (\%) and continuous variables were expressed as mean and SD. Chi-square test and independent sample $t$-test were used to compare the classification variables and continuous variables of MCI group and normal elderly group, respectively. Next, we used different logistic regression models to examine the association between green vegetables intake and MCI, treating green vegetables consumption as a categorical (eat green vegetables every day, yes or no). Model (1) did not control any variables; Model (2) controlled some variables, such as age, education, having hobbies, surfing

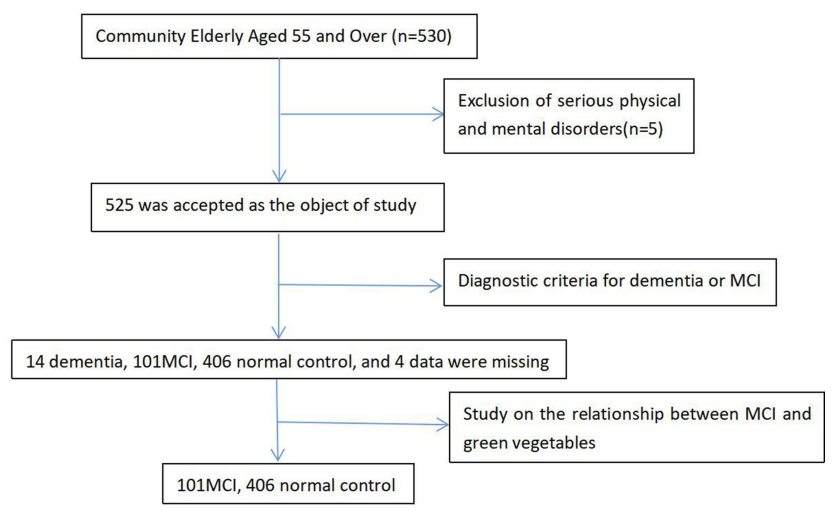

Figure I Research flow chart. This picture describes our research process, criteria for enrollment, and the subjects eventually included in the study. 
Internet, sleep time per night (youth), and long-term residency; Model (3) furtherly controlled other variables, such as the consumption of bean curd and ginger. Then, we made an ROC curve to explore the sensitivity and specificity of the number of green vegetables eaten per week to predict MCI. Two-tailed tests were used at a significance level of $\mathrm{p}<0.05$ for all analyses. The data were analyzed using SPSS 17.0 (IBM Corporation, Armonk, NY, USA).

\section{Results}

Table 1 presents the results of comparison between the normal aging and $\mathrm{MCI}$ groups. The normal aging participants had longer years of education and sleep time per night (youth) as well as higher proportions of surfing Internet, long-term residency in cities, meat and vegetables collocation, eating green vegetables every day, eating bean curd every day, and eating ginger every day compared to the MCI participants. Similarly, the normal aging participants had higher scores of MMSE and MoCA. However, the MCI group was older and had a higher percentage of having hobbies $(\mathrm{p}<0.05)$.

Table 2 shows the results of binary logistic regression analysis. Individuals who ate green vegetables every day had a lower risk of MCI $(\mathrm{OR}=0.236,95 \% \mathrm{CI}, 0.126-$ $0.439, \mathrm{p}<0.001$ ); This relationship remained statistically significant after adjusting for age, education, having hobbies, surfing Internet, sleep time per night (youth), eating habits, and long-term residency in model (2) $(\mathrm{OR}=0.219$, 95\% CI, 0.116-0.412, p < 0.001). Further adjustment for the consumption of bean curd and ginger in model (3) also did not change the results $(\mathrm{OR}=0.218,95 \% \mathrm{CI}, 0.116$ $0.411, \mathrm{p}<0.001)$.

Results from partial correlation analysis (we had controlled age, education, hobby, surfing Internet, sleep time

Table I Description Of The Study Sample Based On Cognitive Status

\begin{tabular}{|c|c|c|c|c|}
\hline Variable & $\operatorname{MCl}(n=101)$ & NC $(n=406)$ & $\mathrm{X}^{2}$ OR $\mathrm{t}$ & $\mathbf{p}$ \\
\hline Age, y & $72.72 \pm 9.901$ & $65.74 \pm 9.661$ & 6.458 & $0.000 *$ \\
\hline Education,y & $5.99 \pm 4.390$ & $9.32 \pm 3.786$ & -6.998 & $0.000 *$ \\
\hline Male, N (\%) & $42(4 I .6)$ & $191(47.0)$ & 0.971 & 0.372 \\
\hline Cigarette smokers, N (\%) & $22(21.8)$ & $103(25.4)$ & 0.560 & 0.520 \\
\hline Alcohol consumption, N (\%) & $15(14.9)$ & $66(16.3)$ & 0.119 & 0.879 \\
\hline Drinking tea, $\mathrm{N}(\%)$ & $43(46.2)$ & $186(45.8)$ & 0.343 & 0.578 \\
\hline Taking exercise, $\mathrm{N}(\%)$ & $68(67.3)$ & $276(68.0)$ & 0.016 & 0.906 \\
\hline Have hobby, $\mathrm{N}(\%)$ & $89(88.1)$ & $306(75.4)$ & 7.639 & $0.005^{*}$ \\
\hline Surfing internet, $N(\%)$ & $6(5.9)$ & $72(17.7)$ & 8.641 & $0.002^{*}$ \\
\hline Sleep time per night (youth),h & $7.391 \pm 1.436$ & $7.725 \pm 0.907$ & -2.230 & $0.028^{*}$ \\
\hline \multicolumn{5}{|l|}{ Eating habits } \\
\hline Vegetarian diet, $\mathrm{N}(\%)$ & $37(36.6)$ & $92(22.7)$ & 12.647 & $0.002^{*}$ \\
\hline Meat diet, $\mathrm{N}(\%)$ & $8(7.9)$ & $16(3.9)$ & & \\
\hline Meat and vegetable collocation, $\mathrm{N}(\%)$ & $56(55.4)$ & $298(73.4)$ & & \\
\hline \multicolumn{5}{|l|}{ Long-term residence } \\
\hline City, N(\%) & $85(84.2)$ & $383(94.3)$ & 19.205 & $0.000 *$ \\
\hline Town, N(\%) & $4(4.0)$ & $14(3.4)$ & & \\
\hline Village, $N(\%)$ & $12(11.9)$ & $9(2.2)$ & & \\
\hline Hypertension, N(\%) & $62(61.4)$ & $38(9.4)$ & 4.613 & 0.125 \\
\hline Diabetes, $N(\%)$ & $21(20.8)$ & $10(2.5)$ & 8.667 & 0.070 \\
\hline Hyperlipidemia, N(\%) & $26(25.7)$ & $15(3.7)$ & 8.102 & 0.088 \\
\hline MMSE & $22.39 \pm 5.992$ & $28.19 \pm 3.172$ & -9.408 & $0.000 *$ \\
\hline MoCA & $16.82 \pm 6.027$ & $27.03 \pm 4.266$ & 16.052 & $0.000 *$ \\
\hline Green vegetables, $\mathrm{N}(\%)$ & $79(78.2)$ & $381(93.8)$ & 23.475 & $0.000 *$ \\
\hline Red meat, $N(\%)$ & $14(13.9)$ & $95(23.4)$ & 5.385 & 0.068 \\
\hline Bread & $5(5.0)$ & $50(12.3)$ & 5.129 & 0.077 \\
\hline Bean curd & $2(1.98)$ & $48(11.8)$ & 9.194 & $0.010^{*}$ \\
\hline Ginger & $3(2.97)$ & $304(74.9)$ & 19.679 & $<0.001^{*}$ \\
\hline
\end{tabular}

Note: ${ }^{*}<<0.05$. 
Table 2 Green Vegetables Consumption (As Categorical Variable) And Mild Cognitive Impairment

\begin{tabular}{|c|c|c|c|c|c|c|c|c|}
\hline \multirow[t]{2}{*}{ Green Vegetables Consumption } & \multirow[t]{2}{*}{ B } & \multirow[t]{2}{*}{ S.E } & \multirow[t]{2}{*}{ Wald } & \multirow[t]{2}{*}{ df } & \multirow[t]{2}{*}{$\mathbf{p}$} & \multirow[t]{2}{*}{ OR } & \multicolumn{2}{|l|}{$95 \% \mathrm{Cl}$} \\
\hline & & & & & & & Upper Limits & Lower Limits \\
\hline Model a & -1.446 & 0.317 & 20.742 & I & 0.000 & 0.236 & 0.126 & 0.439 \\
\hline Model b & -1.518 & 0.323 & 22.115 & I & 0.000 & 0.219 & 0.116 & 0.412 \\
\hline Model c & -1.532 & 0.323 & 22.155 & I & 0.000 & 0.218 & 0.116 & $0.4 I I$ \\
\hline
\end{tabular}

Notes: a, basic model, no adjustment. b, adjusted for age, gender, education, hobby, surfing Internet, sleep time per night (youth), eating habits, and long-term residents. c, adjusted for all variables in model $2+$ the consumption of bean curd, and ginger.

per night (youth), eating habits, and long-term residency) showed consistent results with logistic regression on the reverse relationship between eating green vegetables every day and having MCI $(\mathrm{r}=-0.237, \mathrm{p}<0.001)$. By using an ROC curve, we found out that green vegetables eaten per week could predict whether the subjects would have MCI and the area under the curve was 0.672 (Figure 2).

\section{Discussion}

As far as we know, this was the first study specifically focusing on the relationship between green vegetables consumption and MCI. In this cross-sectional study, we focused on the intrinsic relationship between green vegetables and MCI and controlled factors that might have an impact on cognitive function, such as age, education, gender, etc. And the results showed that eating green vegetables every day

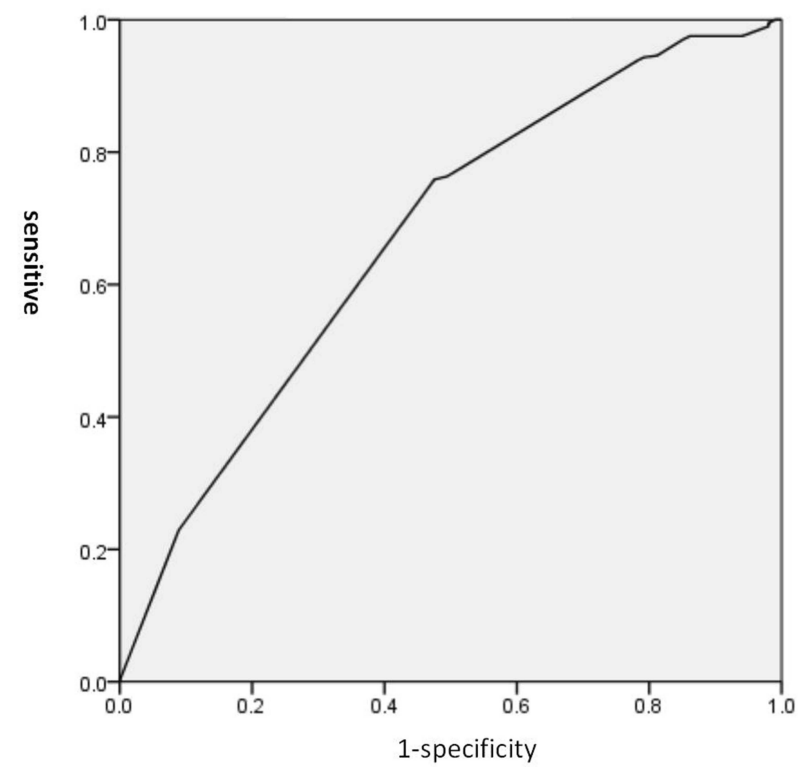

ROC curve of weekly consumption of green vegetables for predicting $\mathrm{MCl}$

Figure 2 ROC curve of weekly consumption of green vegetables for predicting $\mathrm{MCl}$. This figure explains the sensitivity and specificity of using the number of green vegetables eaten per week to predict $\mathrm{MCl}$. might reduce the risk of $\mathrm{MCI}(\mathrm{OR}=0.218,95 \% \mathrm{CI}, 0.116$ $0.411, p<0.001$ ), and this result was independent of age, gender, education, hobby, surfing Internet, sleep time per night (youth), eating habits, long-term residency, and the consumption of specific food (red meat, bread, bean curd as well as ginger). Similarly, the number of vegetables eaten per week could also predict whether subjects would have MCI (the area under the curve was $0.672,95 \% \mathrm{CI}, 61.2-73.2 \%$ ).

Previous studies suggested that greater adherence to Mediterranean diet (the traditional Mediterranean diet refers to a multinutrient dietary profile characterized by high intake of cereals, legumes, fruits, and vegetables; moderate consumption of fish and alcohol especially wine; low-to-moderate intake of dairy products; and low consumption of meat products and saturated fats ${ }^{12}$ ) might be associated with slower cognitive decline and reduced risk of dementia. ${ }^{13-15}$ And some cross-sectional studies conducted in Asia also showed that the consumption of vegetables had potential benefits against dementia. ${ }^{16-18}$ Since there were other factors in the above studies besides green vegetables, the conclusions of our study were partly consistent.

There are several explanations for why green vegetables can prevent cognitive decline. First, oxidative stress and excessive inflammatory reaction are likely to be involved in the pathogenesis of dementia. ${ }^{19}$ Green vegetables are rich in carotenoids, vitamin C, vitamin E, and (n-3) polyunsaturated fatty acids (PUFA), which can inhibit the oxidative stress and inflammatory response effectively, so we speculate that the cognitive protective effect of green vegetables might be related with these antioxidants. ${ }^{20,21}$ Second, inadequate folate status may result in hyperhomocysteinemia, which will increase the risk for cognitive dysfunction. As green vegetables are excellent sources of folate, increasing the intake of green vegetables will be beneficial to the cognitive function for the elderly. ${ }^{22}$ Third, beta-amyloid (A $\beta)$ peptides are involved in the pathogenesis of Alzheimer's disease (AD) and they trigger apoptotic cell death via the activation of caspase-dependent and caspase- 
independent cell death effectors, namely caspase-3 and apoptosis-inducing factor (AIF), respectively. ${ }^{23}$

Accumulating evidence from epidemiological studies shows that consumption of beverages (e.g., red wine and green tea) or food (e.g., fruits and green vegetables) that are enriched in polyphenols is related to a lower risk of dementia such as $\mathrm{AD}^{24}$ And polyphenols are likely to achieve the role of neural protection by inhibiting the activity of caspase- 3 and AIF. ${ }^{25,26}$

We have to admit that there are some limitations in our study. First, it is just a cross-sectional study that cannot determine the causal relationship between eating green vegetables every day and reducing the risk of MCI. Second, the results obtained may not be generalized due to the limited audience. Moreover, some confounding factors were not adjusted.

\section{Conclusion}

In summary, using community-based data in Shanghai, we found out that subjects who eat green vegetables every day have significantly lower odds of MCI than those who do not eat every day. Based on current evidence, we propose that eating green vegetables every day might be a potential preventive measure to slow cognitive decline and neurodegeneration in the elderly.

\section{Acknowledgments}

This work was supported by grants from Shanghai Jiao Tong University Technological Innovation Special Fund (YG2016MS38) and Shanghai Mental Health Center Clinical Research Center (CRC2017ZD02).

\section{Disclosure}

The authors report no conflicts of interest in this work.

\section{References}

1. Iwamoto T. Prevention of dementia on the basis of modification of lifestyle and management of lifestyle-related diseases: a review. Nihon Rinsho. 2014;72(4):612-617.

2. Gu Y, Nieves JW, Stern Y, Luchsinger JA, Scarmeas N. Food combination and Alzheimer disease risk: a protective diet. Arch Neurol. 2010;67(6):699-706. doi:10.1001/archneurol.2010.84

3. Otsuka M. [Analysis of dietary factors in Alzheimer's disease: clinical use of nutritional intervention for prevention and treatment of dementia]. Nihon Ronen Igakkai Zasshi. 2000;37(12):970-973. doi:10.3143/ geriatrics.37.970

4. Kang JH, Ascherio A, Grodstein F. Fruit and vegetable consumption and cognitive decline in aging women. Ann Neurol. 2005;57(5):713720. doi:10.1002/(ISSN)1531-8249

5. Polidori MC, Pratico D, Mangialasche F, et al. High fruit and vegetable intake is positively correlated with antioxidant status and cognitive performance in healthy subjects. $J$ Alzheimers Dis. 2009;17 (4):921-927. doi:10.3233/JAD-2009-1114
6. Xiao S, Li J, Tang M, et al. Methodology of China's national study on the evaluation, early recognition, and treatment of psychological problems in the elderly: the China Longitudinal Aging Study (CLAS). Shanghai Arch Psychiatry. 2013;25(2):91-98. doi:10.3969/ j.issn.1002-0829.2013.02.005

7. Xu X, Xiao S, Rahardjo TB, Hogervorst E. Tofu intake is associated with poor cognitive performance among community-dwelling elderly in China. J Alzheimers Dis. 2015;43(2):669-675. doi:10.3233/JAD141593

8. Petersen RC, Doody R, Kurz A, et al. Current concepts in mild cognitive impairment. Arch Neurol. 2001;58(12):1985-1992. doi:10. 1001/archneur.58.12.1985

9. Folstein MF, Robins LN, Helzer JE. The mini-mental state examination. Arch Gen Psychiatry. 1983;40(7):812. doi:10.1001/archpsyc.1983.01 790060110016

10. Nasreddine ZS, Phillips NA, Bedirian V, et al. The montreal cognitive assessment, MoCA: a brief screening tool for mild cognitive impairment. J Am Geriatr Soc. 2005;53(4):695-699.

11. Wang T, Xiao S, Chen K, et al. Prevalence, incidence, risk and protective factors of amnestic mild cognitive impairment in the elderly in Shanghai. Curr Alzheimer Res. 2017;14(4):460-466. doi:10.2174/1567205013666161122094208

12. Lourida I, Soni M, Thompson-Coon J, et al. Mediterranean diet, cognitive function, and dementia: a systematic review. Epidemiology. 2013;24(4):479-489. doi:10.1097/EDE.0b013e3182944410

13. Solfrizzi V, Frisardi V, Seripa D, et al. Mediterranean diet in predementia and dementia syndromes. Curr Alzheimer Res. 2011;8 (5):520-542. doi:10.2174/156720511796391809

14. Feart C, Samieri C, Barberger-Gateau P. Mediterranean diet and cognitive function in older adults. Curr Opin Clin Nutr Metab Care. 2010;13(1):14-18. doi:10.1097/MCO.0b013e3283331fe4

15. Sofi F, Macchi C, Abbate R, Gensini GF, Casini A. Effectiveness of the mediterranean diet: can it help delay or prevent Alzheimer's disease? J Alzheimers Dis. 2010;20(3):795-801. doi:10.3233/JAD2010-1418

16. Lee CY, Sun Y, Lee HJ, et al. Modest overweight and healthy dietary habits reduce risk of dementia: a nationwide survey in Taiwan. J Prev Alzheimers Dis. 2017;4(1):37-43. doi:10.14283/jpad.2016.123

17. Okubo H, Inagaki H, Gondo Y, et al. Association between dietary patterns and cognitive function among 70-year-old Japanese elderly: a cross-sectional analysis of the SONIC study. Nutr J. 2017;16(1):56. doi:10.1186/s12937-017-0273-2

18. Kitamura K, Watanabe Y, Nakamura K, et al. Modifiable factors associated with cognitive impairment in 1,143 Japanese outpatients: the Project in Sado for Total Health (PROST). Dement Geriatr Cogn Dis Extra. 2016;6(2):341-349. doi:10.1159/000447963

19. Meydani M. The Boyd Orr lecture. nutrition interventions in aging and age-associated disease. Proc Nutr Soc. 2002;61(2):165-171. doi:10.1079/PNS2002144

20. Kesse-Guyot E, Andreeva VA, Ducros V, et al. Carotenoid-rich dietary patterns during midlife and subsequent cognitive function. $\mathrm{Br} J$ Nutr. 2014;111(5):915-923. doi:10.1017/S0007114513003188

21. Shiraseb F, Siassi F, Sotoudeh G, et al. Association of blood antioxidants status with visual and auditory sustained attention. Nutr Neurosci. 2015;18(8):345-354. doi:10.1179/1476830515Y.0000000032

22. Rampersaud GC, Kauwell GP, Bailey LB. Folate: a key to optimizing health and reducing disease risk in the elderly. $J$ Am Coll Nutr. 2003;22(1):1-8. doi:10.1080/07315724.2003.10719270

23. Bastianetto S, Krantic S, Chabot JG, Quirion R. Possible involvement of programmed cell death pathways in the neuroprotective action of polyphenols. Curr Alzheimer Res. 2011;8(5):445-451. doi:10.2174/ 156720511796391854

24. Letenneur L, Proust-Lima C, Le Gouge A, Dartigues JF, BarbergerGateau P. Flavonoid intake and cognitive decline over a 10-year period. Am J Epidemiol. 2007;165(12):1364-1371. doi:10.1093/aje/ kwm036 
25. Campos-Esparza MR, Sanchez-Gomez MV, Matute C. Molecular mechanisms of neuroprotection by two natural antioxidant polyphenols. Cell Calcium. 2009;45(4):358-368. doi:10.1016/j.ceca. 2008.12.007
26. Bournival J, Quessy P, Martinoli MG. Protective effects of resveratrol and quercetin against MPP+ -induced oxidative stress act by modulating markers of apoptotic death in dopaminergic neurons. Cell Mol Neurobiol. 2009;29(8):1169-1180. doi:10.1007/s10571-009-9411-5

\section{Publish your work in this journal}

Neuropsychiatric Disease and Treatment is an international, peerreviewed journal of clinical therapeutics and pharmacology focusing on concise rapid reporting of clinical or pre-clinical studies on a range of neuropsychiatric and neurological disorders. This journal is indexed on PubMed Central, the 'PsycINFO' database and CAS, and is the official journal of The International Neuropsychiatric Association (INA). The manuscript management system is completely online and includes a very quick and fair peer-review system, which is all easy to use. Visit http://www.dovepress.com/testimonials.php to read real quotes from published authors.

Submit your manuscript here: https://www.dovepress.com/neuropsychiatric-disease-and-treatment-journal 